\title{
Unraveling the Dual Character of Sulfur Atoms on Sensitizers in Dye- Sensitized Solar Cells
}

Sadig Aghazada, ${ }^{\dagger}$ Peng Gao, ${ }^{\dagger}$ Aswani Yella, ${ }^{\ddagger}$ Thomas Moehl, ${ }^{\ddagger}$ Joël Teuscher, $^{\S}$ Jacques-E. Moser, ${ }^{\S}$ Michael Grätzel, ${ }^{\ddagger}$ and Mohammad Khaja Nazeeruddin ${ }^{*},+\perp$

${ }^{\dagger}$ Group for Molecular Engineering of Functional Materials, Institute of Chemical Sciences and Engineering, École Polytechnique Fédérale de Lausanne, CH-1950 Sion, Switzerland

${ }^{\ddagger}$ Laboratory of Photonics and Interfaces and ${ }^{\S}$ Group for Photochemical Dynamics, Institute of Chemical Sciences and Engineering, École Polytechnique Fédérale de Lausanne, Station 6, CH-1015 Lausanne, Switzerland

${ }^{\perp}$ Center of Excellence for Advanced Materials Research (CEAMR), King Abdulaziz, University, Jeddah, Saudi Arabia

Supporting Information

ABSTRACT: Cyclometalated ruthenium sensitizers have been synthesized that differ with number of thiophene units on the auxiliary ligands. Sensitizers possessing four (SA25, SA246, and SA285) or none (SA282) sulfur atoms in their structures, were tested in solar cell devices employing $\mathrm{I}_{3}{ }^{-} / \mathrm{I}^{-}$redox mediator, enabling an estimation of the influence of sulfuriodine/iodide interactions on dye-sensitized solar cell (DSC) performance. Power conversion efficiencies over $6 \%$ under simulated AM 1.5 illumination ( 1 Sun) were achieved with all the sensitizers. Consistently higher opencircuit voltage $\left(V_{\mathrm{OC}}\right)$ and fill factor $(\mathrm{FF})$ values were measured using SA282. Scrutinizing the DSCs with these dyes by transient absorption spectroscopy (TAS) and electrochemical impedance spectroscopy (EIS) indicate that sulfur atom induced recombination cancels favorable increased regeneration resulting in decreased power conversion efficiencies (PCEs). The data indicate that, to reduce charge recombination channels, the use of sulfurcontaining aromatic rings should be avoided if possible in the dye structure when $\mathrm{I}_{3}{ }^{-} / \mathrm{I}^{-}$redox mediator is used.

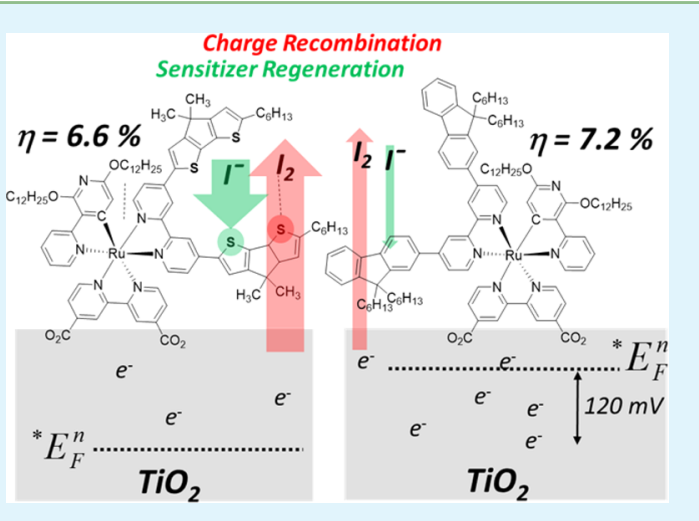

KEYWORDS: dye-sensitized solar cells, ruthenium complexes, iodine electrolyte, charge recombination

\section{INTRODUCTION}

Humanity's needs for energy, coupled with depleting fossil fuels and increasing greenhouse gases, distinguish the efficient conversion of solar energy as a hot research focus. ${ }^{1}$ Many types of solar cell materials from classic monocrystalline silicon to recent perovskites have been developed. ${ }^{2-4}$ In comparison to many other technologies, dye-sensitized solar cells (DSCs) yield power conversion efficiencies (PCEs) of $14.3 \%$ with significantly lower cost. ${ }^{5}$ A standard DSC consists of a photoanode and a cathode sandwiching liquid electrolyte in between (Figure 1). ${ }^{6}$ The photoanode is made of a conductive glass covered with a mesoporous layer of $\mathrm{TiO}_{2}$ semiconductor, which is sensitized in the visible solar region by a monolayer of dye molecules. The cathode is usually also made of conductive glass covered with a $\mathrm{Pt}$ catalyst to facilitate fast redox processes. $^{7}$ Upon photoexcitation, dye molecules inject electrons into the conduction band of the semiconductor and then the formed oxidized dyes are reduced back by the redox mediator present in the electrolyte. ${ }^{8,9}$ Collection of electrons from the conduction band and diffusion of holes in the electrolyte toward the counter electrode and the following hole-electron recombination on the counter electrode closes the cycle.
Processes taking places on different parts of DSCs were extensively studied. ${ }^{10}$ Among the pertinent problems, electron-hole recombination on the working electrode remains the main factor limiting the power conversion efficiency. ${ }^{11}$ The charge recombination may take place in two electron sinks: photooxidized sensitizer and the oxidized component of redox mediator. ${ }^{12}$ Among these two, the recombination of the conduction band electrons with the oxidized redox component is more devastating. ${ }^{13}$ In the DSCs, employing cobalt(III/II) redox mediator in the electrolyte, the strategy to diminish charge recombination is that sensitizers are endowed with bulky alkyl chains to keep cobalt(III) ions away from the surface. ${ }^{14-20}$ However, there is no such a universal rule for the DSCs employing $\mathrm{I}_{3}^{-} / \mathrm{I}^{-}$mediator, making it hard to foresee the sensitizer's ability to prevent recombination. In the sensitizer design one would greatly benefit from any rule of thumb about how the sensitizer structure affects the recombination rate.

Many works have shown that the sulfur atoms in a dye structure prone to induce dye-iodine interaction, which

Received: July 19, 2016

Accepted: September 9, 2016

Published: September 9, 2016 


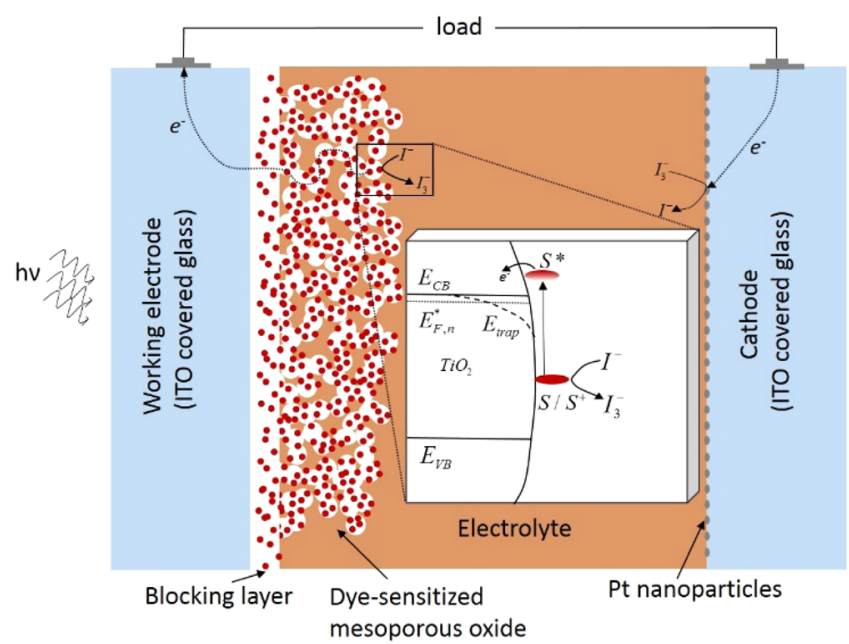

Figure 1. Schematic representation of DSC.

increases iodine concentration in the vicinity of mesoporous oxide resulting in a higher recombination. ${ }^{21-25}$ Using TG6 and K19 ruthenium based sensitizers (Figure 2), which have sulfur and oxygen atoms on the ancillary bipyridine ligand respectively, O'Regan et al. studied the change in the opencircuit voltage $\left(V_{\mathrm{OC}}\right)$ in the DSCs. The DSC with TG6 exhibited $20 \mathrm{mV}$ lower $V_{\mathrm{OC}}$ than the DSC with $\mathrm{K} 19 .{ }^{26}$ With all the rest of the parameters identical, this result was solely related to the 2.3 times lower recombination lifetime in the case of TG6. The same effect was shown to take place for the donor (D) $-\pi$-acceptor (A) organic dyes, where additional thiophene (T3 in comparison to T1 in Figure 2) moiety in the $\pi$-bridge results in $V_{\text {OC }}$ reduction. ${ }^{27-29}$ Calculations indicate that iodine molecules preferentially bind to the sulfur atoms in the thiophenes. On the other hand, Robson et. al. established that substituting oxygen in the hexyloxy groups on the donor part of sensitizer (Dye-O) to the sulfur (Dye-S) (Figure 2) results in increased $\mathrm{PCE},{ }^{30}$ due to an increase in $V_{\mathrm{OC}}$ of $64 \mathrm{mV}$. This is understood by faster regeneration in the case of Dye-S and no substantial difference in recombination rates between Dye-S and Dye-O. Moreover, recently, the role of halogen bonding in increased dye regeneration rate was also established. ${ }^{31}$

\section{RESULTS AND DISCUSSION}

Thiophene and other sulfur-containing aromatic and polyaromatic rings enable wide-range tuning of spectral and electrochemical properties of a material. ${ }^{32,33}$ It is not surprising that the majority of sensitizers possess one or more sulfurcontaining aromatics. Considering the role of sulfur atoms in initiating both favorable regeneration and unfavorable recombination processes, predictions on whether addition of a sulfur atom into the structure will increase or decrease $V_{\mathrm{OC}}$ are hard to make. To address this issue, we developed four ruthenium sensitizers and assembled DSCs (Figure 3). All four sensitizers

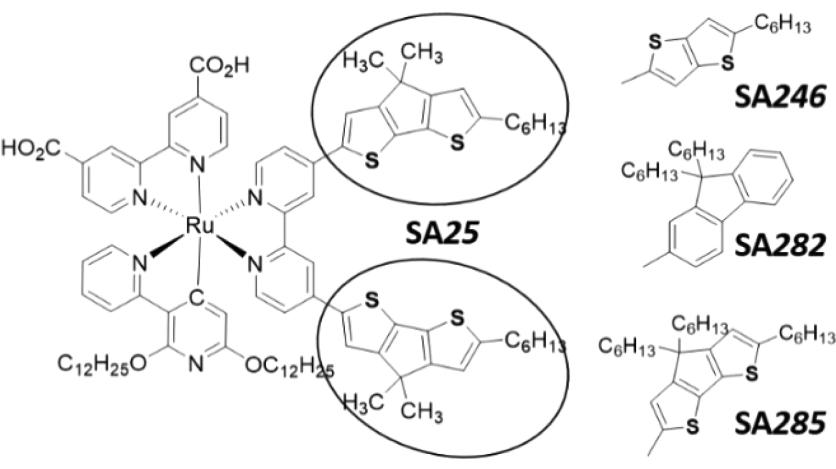

Figure 3. Molecular structures of cyclometalated ruthenium(II) complexes employed as sensitizers in DSCs in this study.

possess similar cyclometalating and anchoring ligands, but different ancillary ligands. Polyaromatic moieties on the bases of cyclopentadienodithiophene (SA22, SA285), thienothiophene (SA246), and fluorene (SA282) were attached to the corresponding ancillary ligands. One of the sensitizers has no sulfur atom in its structure, and the rest possess four sulfur atoms, making a reasonable comparison.

To relate the $V_{\mathrm{OC}}$ change solely to the role of sulfur atoms, we have to first exclude other possible causes. Generally, the $V_{\mathrm{OC}}$ is a difference between the quasi-Fermi energy level $\left({ }^{*} E_{\mathrm{F}}^{n}\right)$ for electrons in mesoporous oxide $\left(\mathrm{TiO}_{2}\right)$ and the oxidation potential of the redox couple. ${ }^{34}$ Trap and conduction band state distributions are important factors determining the steady-state concentration of electrons and thus the $* E_{\mathrm{F}}^{n}$. Since $V_{\mathrm{OC}}$ is achieved when the flux of injected electrons is equal to the flux of recombined electrons, for a reasonable comparison, the electron recombination flux should follow the same kinetics. In our discussion we need to consider these points.

Optical and electrochemical properties of SA sensitizers supported with quantum-mechanical calculations are thoroughly discussed in our previous work ${ }^{35}$ and summarized in Figure 4. The absorption spectra red shift in the order SA282 < SA246 < SA284 < SA285 (Figure 4). Oxidation potentials for the series vary around $0.9 \mathrm{~V}$ versus normal hydrogen electrode (NHE), which should guarantee an analogous regeneration mechanism with iodide. From the $E_{0-0}$ values, the estimated excited state oxidation potentials are negative enough to

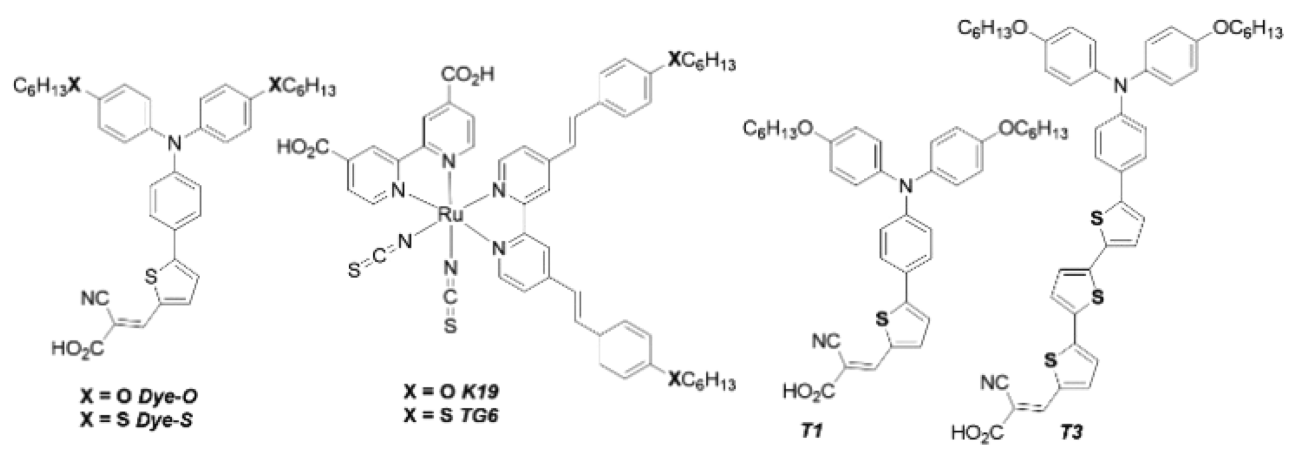

Figure 2. Molecular structures of some organic $\mathrm{D}-\pi-\mathrm{A}$ and ruthenium isothiocyanate complexes studied in the literature. 

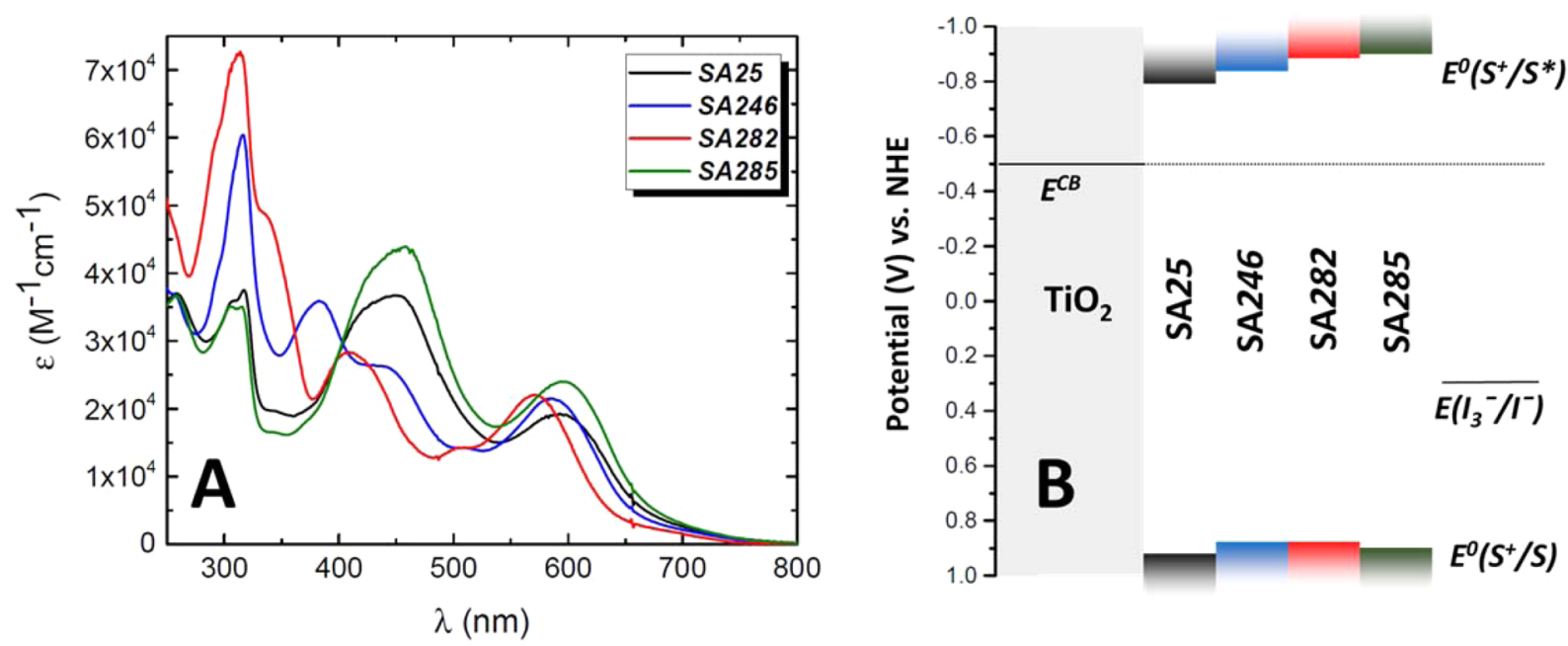

Figure 4. (A) Absorption spectra of SA dyes in $10^{-5} \mathrm{M}$ dichloromethane solutions. (B) Energy diagram showing the sensitizers, and ground and excited state oxidation potentials along with iodine oxidation potential in Z960 electrolyte.

guarantee an efficient excited electron injection. It is worth mentioning that, according to density functional theory (DFT) calculations, the highest occupied molecular orbital (HOMO) is localized on the $\mathrm{Ru} \mathrm{t}_{2 \mathrm{~g}}$ orbitals only for SA282. For SA246 the HOMO is distributed also over one side of the ancillary ligand, while for SA25 and SA285 it is distributed over both sides. The lowest unoccupied molecular orbital (LUMO) is localized on the anchoring ligand for all the sensitizers.

The DSCs employing SA sensitizers and iodine based electrolyte were assembled. The electrolytes were optimized based on Z960 to achieve high efficiencies. The $J-V$ curves are presented in Figure 5. The short-circuit current varies in the

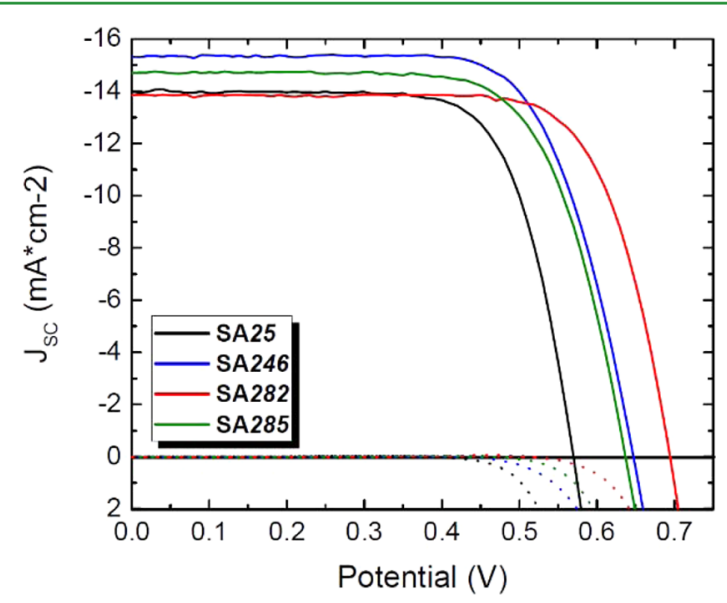

Figure 5. Photocurrent density versus applied voltage under 1.5 AM irradiance and in the dark.

range $14-16 \mathrm{~mA} / \mathrm{cm}^{2}$ and increases in the following order: SA282 < SA25 < SA285 < SA246 (Table 1). Usually in the DSCs a dye with a more red-shifted absorption spectrum provides higher photocurrent. However, that is not the case for this series of sensitizers. The open-circuit potential varies in a big range from 570 to $694 \mathrm{mV}$, with the order SA25 < SA285 < SA246 < SA282. Interestingly, the SA282 sensitizer provides the highest $V_{\mathrm{OC}}$ and the lowest $J_{\mathrm{SC}}$, leading to the best performing DSC with a PCE of $7.2 \%$.

To understand this phenomenon, all DSCs were studied by the means of transient absorbance spectroscopy (TAS). Two
Table 1. Photovoltaic Performance of DSCs

$\begin{array}{lccccc}\text { sensitizer } & \begin{array}{c}J_{\mathrm{SC}}{ }^{a} \\ \left(\mathrm{~mA} \mathrm{~cm}^{-2}\right)\end{array} & \begin{array}{c}V_{\mathrm{OC}} \\ (\mathrm{mV})\end{array} & \begin{array}{c}\mathrm{FF} \\ (\%)\end{array} & \begin{array}{c}\text { PCE } \\ (0.1 \text { Sun })\end{array} & \begin{array}{c}\text { PCE } \\ (1 \text { Sun })\end{array} \\ \text { SA25 } & 13.98 & 570 & 62.4 & 6.8 & 6.6 \\ \text { SA246 } & 15.32 & 647 & 70.6 & 6.7 & 7.1 \\ \text { SA282 } & 13.84 & 694 & 73.8 & 7.1 & 7.2 \\ \text { SA285 } & 14.71 & 634 & 69.9 & 6.9 & 6.7\end{array}$

${ }^{a}$ Cell active area was $0.28 \mathrm{~cm}^{2}$ and black mask with open area 0.159 $\mathrm{cm}^{2}$ was used during the measurements.

sets of devices, with and without redox mediator in the electrolyte, have been prepared. Sensitizer in the unbiased DSC was excited with low intensity, ca. $40 \mu \mathrm{J} \mathrm{cm}^{-2}$, with pulsed laser light at $510 \mathrm{~nm}$, to result in no more than one electron per nanoparticle. The probe was monitored at $900 \mathrm{~nm}$, based on the oxidized dye absorption spectra. Care needs to be taken, since this condition is far from the maximum power point condition, where the electron density reaches 20 electrons per particle. In the first set of devices, lacking redox mediator, the only process to be considered to fit the transient absorbance decay is electron recombination with the photooxidized sensitizer $\left(\tau_{1}=1 / k_{1}\right)$. Thus, from the monoexponential fitting, the photooxidized sensitizer's lifetime was obtained. In the presence of the redox couple, the transient absorbance spectra decay much faster, which is due to fast photooxidized dye regeneration. The photooxidized dye lifetime then is determined not only by recombination, but also by regeneration: $\tau_{\text {reg }}=1 /\left(k_{1}+k_{\text {reg }}\right)$. Thus, the regeneration yield can be estimated as $\eta=\tau_{1} /\left(\tau_{1}+\tau_{\text {reg }}\right)$. Except for SA282 and SA285, all sensitizers regenerate with at least $96 \%$ efficiency. SA282 regenerates with $63 \%$ and SA285 with $73 \%$ yield. These results are not surprising, considering that sulfur atoms in the sensitizer structure catalyze regeneration with iodide. Sluggish regeneration of SA282 compared to other sensitizers is due to the absence of any sulfur atoms in the structure. If compared to SA246, which has a similar oxidation potential, we may notice that the drop in the regeneration yield is huge. This result underlines the importance of sulfur atoms in efficient regeneration. ${ }^{36}$ For the case of SA285, comparison to SA25 would be more reasonable, since they both have the same substituents but with different alkyl chain lengths. The drop in the regeneration efficiency for SA285 in comparison to SA25 

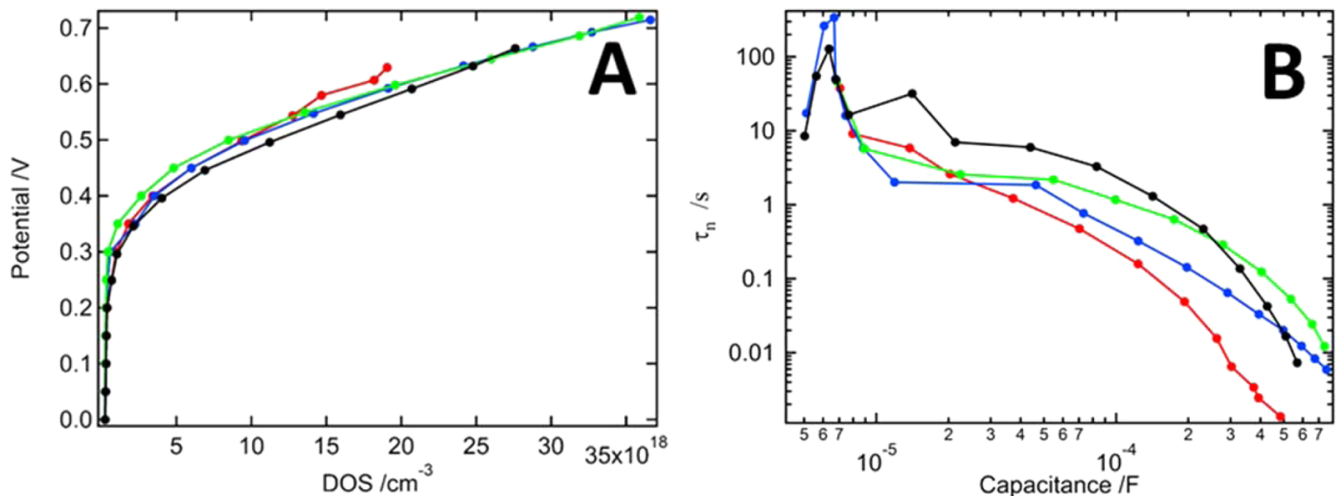

Figure 6. (A) Density of states and (B) electron lifetime obtained from EIS analyses for SA25 (red), SA246 (blue), SA282 (green), and SA285 (black).

could be due to longer alkyl chains, which prevent efficient interaction between the sensitizer and iodide.

Thus, the transient absorbance measurements confirmed that the presence of the sulfur atoms on the aromatic substituents potentiate faster, with thus more efficient sensitizer regeneration. However, since the regeneration with iodide is considered to take place through an inner-sphere electron transfer mechanism, we may not completely exclude the role of the frontier orbitals, meaning the HOMO of reductant and the LUMO of oxidant. ${ }^{37,38}$ In our case, the LUMO of photooxidized dye, which is qualitatively related to the HOMO of neutral dye in comparison to other sensitizers, is localized on the ruthenium $t_{2 g}$ orbitals for SA282 and is not distributed over the ligands, making it difficult to achieve an efficient overlap with the reductant's HOMO.

To investigate the internal electronic features of the optimized DSCs, we conducted electrochemical impedance spectroscopy (EIS) measurements in the dark and at different forward biases applied. Transmission line models developed by Bisquert et al. were used to fit the impedance spectra. ${ }^{39,40}$ The main parameters such as the titania charge recombination resistance $R_{\mathrm{cr}}$ and chemical potential $C_{\mathrm{m}}$, describing the density of states accessible for electrons, were extracted. According to the equation $\tau=R C_{\mathrm{m}}$, the apparent electron recombination $\left(\tau_{\text {rec }}\right)$ lifetime was obtained.

In Figure 6A the charge density, calculated from the chemical potential, for four DSCs as a function of applied voltage are presented. Since there is no substantial difference between them, we may conclude that the conduction band positions for four DSCs with SA dyes are identical. From this point, we may conclude that for this series of four sensitizers the DSC voltage difference is not due to conduction band change. The shift in the conduction band position is usually caused by different components in electrolyte or by the adsorption mode of the sensitizer. Considering that here we analyze DSCs with similar electrolyte compositions and that investigated sensitizers have close structures, a similar conduction band position was anticipated. In Figure $6 \mathrm{~B}$ the recombination lifetime versus capacitance is presented. Depending on the sensitizer, the recombination lifetime changes dramatically. As we can see, the highest recombination lifetime was achieved with SA282 and the lowest one was achieved with SA25. We need to note here that the lifetimes obtained from the EIS measurements, which were conducted in the dark with applied bias close to the open circuit voltage, are usually higher than the lifetimes obtained from the EIS measurements at $V_{\mathrm{OC}}$ under 1 Sun illumination.
The main difference between these two cases is that the photooxidized dyes in the latter case can be regenerated with iodide and result in a gradient of $\mathrm{I}_{3}{ }^{-}$concentration between two electrodes with lower concentration in the vicinity of titania. In the former case there is no electrolyte gradient present. ${ }^{41}$ Thus, electron recombination lifetimes obtained from EIS in the dark under forward bias should be treated with care. Nevertheless, these values can be used for estimation. Since electron recombination lifetimes vary among four DSCs under similar forward biases, the steady-state concentration of electrons in $\mathrm{TiO}_{2}$ should be different. The relative change in $V_{\mathrm{OC}}$ caused by $* E_{\mathrm{F}}^{n}$ due to the changes in the recombination lifetimes can be calculated according to the equation

$$
\Delta V_{\mathrm{OC}}=\left(\frac{k_{\mathrm{B}} T}{q}\right) \ln \left(\frac{\tau_{\mathrm{rec}}(\mathrm{S} 2)}{\tau_{\mathrm{rec}}(\mathrm{S} 1)}\right)
$$

where $k_{\mathrm{B}}, T$, and $q$ are the Boltzmann constant, temperature, and electron charge; $\tau_{\text {rec }}(\mathrm{S} 2)$ and $\tau_{\text {rec }}(\mathrm{S} 1)$ are electron recombination lifetimes for the dyes. The total changes of $V_{\mathrm{OC}}$, as a result of conduction band shift and various electron recombination lifetimes, are brought in Table 2 and compared

Table 2. Comparison of the Change in $V_{\mathrm{OC}}$ Values Estimated from EIS Analyses and Obtained from $J-V$ Measurements

$\begin{array}{ccccc}\text { sensitizer } & \Delta E_{\mathrm{CB}}(\mathrm{mV}) & \Delta V^{b}(\mathrm{mV}) & \Delta V_{\mathrm{OC}}{ }^{c}(\mathrm{mV}) & \Delta V_{\mathrm{OC}}{ }^{d}(\mathrm{mV}) \\ \text { SA25 } & & & & \\ \text { SA246 } & -9 & 68 & 59 & 77 \\ \text { SA282 } & -2 & 99 & 97 & 124 \\ \text { SA285 } & -31 & 78 & 47 & 64\end{array}$

${ }^{a}$ Values for all devices are brought into reference to the one with SA25. ${ }^{b}$ Due to $\tau_{\text {rec }}$. In eq $1, \tau_{\text {rec }}(\mathrm{S} 1)$ was taken for SA25. ${ }^{c} \Delta V_{\mathrm{OC}}=\Delta V$ $+\Delta E_{\mathrm{CB}} \cdot{ }^{d}$ From $J-V$.

to the values obtained from $J-V$ measurements. Very good agreement is obtained. From here, we may conclude that higher $V_{\mathrm{OC}}$ achieved with SA282 is the result of increased electron recombination lifetime. This point is in agreement with previous studies, which indicate that sulfur-containing sensitizers catalyze electron recombination. However, we need to show that the various electron recombination lifetimes are not due to present pinholes on the sensitized mesoporous semiconductor.

To analyze this aspect, we conducted X-ray photoemission spectroscopy (XPS) measurements with bare and sensitized mesoporous semiconductor films. We compared the drop in 
the Ti $2 p_{3 / 2}$ and Ti $2 p_{1 / 2}$ signal intensities in reference to the ones obtained for the bare titania film, with the assumption that the efficient coverage should decrease the signal intensity. When full coverage is present, the factor influencing the signal damping is the thickness of the adsorbed layer. Here, considering that SA dyes possess alike sizes and structures, we assume that the layer thickness varies negligibly. For the cobalt based electrolytes, where there is no dye redox mediator interaction discussed in the literature, it was shown that the effective coverage correlates with the open-circuit voltage, and low voltages were related to a thinner monolayer. ${ }^{42,43}$ Since the sizes of sensitizers presented in this work do not vary strongly, weaker damping of the photoemission signals could be related to the presence of pinholes in the sensitizer monolayer.

The best surface protection is achieved with sensitizer SA285 and the worst is achieved with SA25. SA246 and SA282 result in a similar damping (Figure 7 ). These results indicate that the

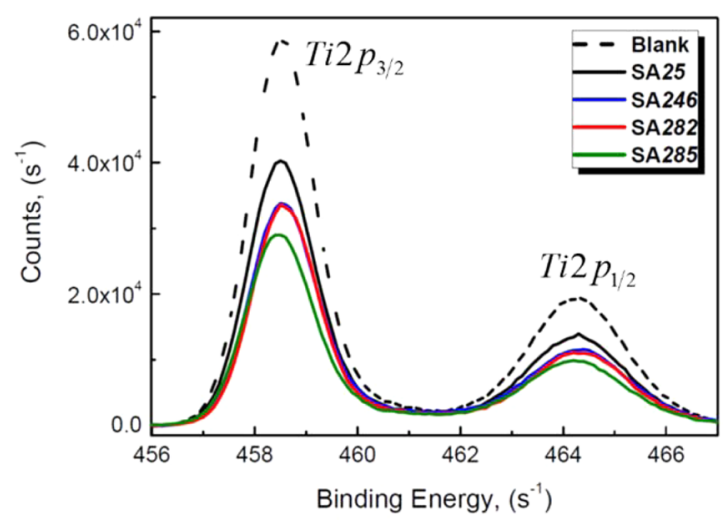

Figure 7. Ti $2 p$ XPS spectra of bare (blank) and sensitized titania films.

changes in voltages for SA246 and SA282 are not due to present pinholes. For SA25 the drastically lower $V_{\mathrm{OC}}$ could be related to both the increased recombination via sulfur iodine interaction and pinholes present on the adsorbed surface.

\section{CONCLUSION}

Thus, we have studied the influence of sulfur-iodine/iodide interactions on DSC performance with four ruthenium(II) cyclometalated sensitizers employing iodine-based electrolyte. The dual role of sulfur atom containing aromatic substituents in the photovoltaic performance have been analyzed and explained on the basis of transient absorption, electrochemical impedance, and X-ray photoemission spectroscopies. We observed the trade-off between strongly enhanced dye regeneration and increased recombination owing solely to the sulfur atom substituents, and in total it has a drastic negative effect on the photovoltaic performance. Without a sulfur atom in its structure, SA282 provides the highest efficiency due to the much increased electron recombination lifetime, which suppressed the negative effect of a blue-shifted absorption spectrum and lowest dye regeneration yield. Thus, based on this study, the introduction of sulfur-containing aromatic rings in a sensitizer should be rechecked because it might not benefit the total performance of the final devices.

\section{EXPERIMENTAL SECTION}

Device Fabrication. Working Electrode. Fluorine-doped tin oxide (FTO) covered conductive glass (Nippon Sheet Glass, NSG, $10 \Omega$ / sq) was twice treated with $0.06 \mathrm{M} \mathrm{TiCl}_{4}(\mathrm{aq})$ at $70{ }^{\circ} \mathrm{C}$ for $1 / 2 \mathrm{~h}$ and washed with excess distilled water. Afterward, $8 \mu \mathrm{m}$ of titania film containing $18 \mathrm{~nm}$ size particles and then an additional $5 \mu \mathrm{m}$ thick paste of $400 \mathrm{~nm}$ size particles were screen-printed (Solaronix). Then, the electrode was sintered at up to $500{ }^{\circ} \mathrm{C}$ according to the program described in the literature. ${ }^{6}$ Before preparing a device, the electrode was treated with $0.025 \mathrm{M} \mathrm{TiCl}_{4}(\mathrm{aq})$ at $70{ }^{\circ} \mathrm{C}$ for $1 / 2 \mathrm{~h}$, washed with excess distilled water, dried in air, and heated at $500{ }^{\circ} \mathrm{C}$ for $1 / 2 \mathrm{~h}$. Then, the electrode was dipped into a $0.2 \mathrm{mM}$ solution of sensitizer in EtOH-THF (7:3) and kept for $12 \mathrm{~h}$. Afterward, the electrode was washed with excess acetonitrile and a cell was assembled (vide infra).

Counter Electrode. FTO covered glass (TEC 7, Dyesol) with two predrilled holes was heated at $410{ }^{\circ} \mathrm{C}$ for $15 \mathrm{~min}$ and cooled to room temperature, and $5 \mathrm{mM}$ solution of $\mathrm{H}_{2} \mathrm{PtCl}_{6}$ in isopropanol was dropcast onto it. After drying at room temperature, the electrode was again annealed at $410{ }^{\circ} \mathrm{C}$ for $20 \mathrm{~min}$.

Electrolyte. The electrolyte composition was as follows: $1.0 \mathrm{M} \mathrm{1,3-}$ propylmethylimidazolium iodide (PMII), $50 \mathrm{mM} \mathrm{LiI}, 30 \mathrm{mM} \mathrm{I}_{2}, 0.5 \mathrm{M}$ tert-butylpyridine ( $\left.{ }^{\mathrm{t}} \mathrm{BP}\right)$, and $0.1 \mathrm{M}$ guanidinium thiocyanate (GNCS) in acetonitrile.

Cell Assembly. Hot-melt ionomer (Syrlyn, DuPont), $25 \mu \mathrm{m}$ thick, was sandwiched in between the working and counter electrodes, and the electrodes were gently pressed while being heated at $120^{\circ} \mathrm{C}$ for 10 s. The electrolyte was inserted through the hole in the counter electrode, and holes were sealed with a piece of hot-melt ionomer and thin glass at $120^{\circ} \mathrm{C}$.

Photovoltaic Characterization. ${ }^{35}$ A solar simulator (Osram XBO 450) with a $450 \mathrm{~W}$ xenon lamp and a sunlight filter Schitt K113 Tempax (Präzisions Glas \& Optik GmbH, Germany) was used to simulate AM 1.5 solar spectra with less than 4\% error. A silicon photodiode was used to control the lamp power. At different sun intensities, applying external bias to the device with a Keithley digital source meter (Keithley 2400, USA), the current-voltage characteristics were obtained. Current measurement was set up to be delayed by $80 \mathrm{~ms}$ from applying voltage.

EIS, TAS, and XPS Analyses. EIS measurements were performed by a Biologic SP300 (BioLogic, France) in a frequency range between $7 \mathrm{MHz}$ and $0.1 \mathrm{~Hz}$ for potentials from $0 \mathrm{~V}$ to about $V_{\mathrm{OC}}$ (with a $20 \mathrm{mV}$ sinusoidal ac perturbation) in $50 \mathrm{mV}$ steps. A stabilization time of $20 \mathrm{~s}$ at each measurement potential was applied.The resulting impedance spectra were analyzed with the ZView software (Scribner Associate) on the basis of the transmission line model. ${ }^{44}$ The potentials of the EIS results are corrected for $I R$ drop. The real potential $\left(V_{\text {real }}\right)$ to the device is determined by the subtraction of the voltage drop $\left(V_{\text {Drop }}\right)$ from the applied potential $\left(V_{\text {applied }}\right)$. The voltage drop is calculated by the integration of the sum of all series resistances $\left(R_{\text {Aseries }}\right)$ over the current passed $\left(V_{\text {real }}=V_{\text {applied }}-V_{\text {Drop }}\right.$; with $V_{\text {Drop }}=\int R_{\text {Aseries }} \mathrm{d} I$, where $\left.R_{\text {Aseries }}=R_{\mathrm{s}}+R_{\mathrm{ce}}+R_{\text {Electrolyte }}\right)$.

Device preparations for the TAS measurements were analogous to the solar cell preparations with only two differences: first, the scattering layer of titania consisting of $400 \mathrm{~nm}$ size nanoparticles was not used; second, the platinum catalysts were not deposited on the counter electrode. Devices were subjected to pulsed laser excitation from an Ekspla NT-342 Nd:YAG laser at $20 \mathrm{~Hz}$, pumping an OPO tuned at $510 \mathrm{~nm}$ (full width at half-maximum $(\mathrm{fwhm}) \approx 5 \mathrm{~ns}$ ). The laser pulse was attenuated to $40 \mu \mathrm{J} \mathrm{cm}^{-2}$ pulse $^{-1}$. The beam was expanded by a planoconcave lens to irradiate the whole sample, whose surface was kept at a $45^{\circ}$ angle to the excitation and probe beams. The probe light was produced by a $250 \mathrm{~W}$ halogen bulb (64655 HLX, Osram). It was passed through a series of cutoff filters up to $780 \mathrm{~nm}$ to remove unwanted light bias, focused onto the sample, and passed through a monochromator tuned at the desired wavelength (Omni- $\lambda$ 150, Oriel) prior to being detected by a fast InGaAs diode (SM05PD5A, Thorlabs). Transient signals were measured through a $1 \mathrm{k} \Omega$ load with an oscilloscope (DPO 7104, Tektronix). Satisfactory signal-to-noise ratios were typically obtained by averaging over 1500 laser shots, and a Savitsky-Golay smoothing algorithm was applied to raw data.

XPS analyses were conducted using a PHI VersaProbe II scanning XPS microscope (Physical Instrument AG, Germany) with a 
monochromatic $\mathrm{Al} \mathrm{K} \alpha \mathrm{X}$-ray source $(1486.6 \mathrm{eV})$. The electron takeoff angle was set at $45^{\circ}$.

\section{ASSOCIATED CONTENT}

\section{S Supporting Information}

The Supporting Information is available free of charge on the ACS Publications website at DOI: 10.1021/acsami.6b08882.

Additional EIS and TAS data in Figures S1 and S2 (PDF)

\section{AUTHOR INFORMATION}

\section{Corresponding Author}

*E-mail: mdkhaja.nazeeruddin@epfl.ch.

\section{Notes}

The authors declare no competing financial interest.

\section{ACKNOWLEDGMENTS}

The authors thank Nicholas Xanthopolous for conducting the XPS measurements.

\section{REFERENCES}

(1) Lewis, N. S.; Nocera, D. G. Powering the Planet: Chemical Challenges in Solar Energy Utilization. Proc. Natl. Acad. Sci. U. S. A 2006, 103, 15729-15735.

(2) Gao, P.; Grätzel, M.; Nazeeruddin, M. K. Organohalide Lead Perovskites for Photovoltaic Applications. Energy Environ. Sci. 2014, 7, 2448 .

(3) Liang, D.; Kang, Y.; Huo, Y.; Chen, Y.; Cui, Y.; Harris, J. S. HighEfficiency Nanostructured Window GaAs Solar Cells. Nano Lett. 2013, 13, 4850-4856.

(4) O’Regan, B.; Grätzel, M. A Low-Cost, High-Efficiency Solar Cell Based on Dye-Sensitized Colloidal TiO2 Films. Nature 1991, 353, 737-740.

(5) Kakiage, K.; Aoyama, Y.; Yano, T.; Oya, K.; Fujisawa, J.; Hanaya, M. Highly-Efficient Dye-Sensitized Solar Cells with Collaborative Sensitization by Silyl-Anchor and Carboxy-Anchor Dyes. Chem. Commun. 2015, 51, 15894-15897.

(6) Ito, S.; Murakami, T. N.; Comte, P.; Liska, P.; Grätzel, C.; Nazeeruddin, M. K.; Grätzel, M. Fabrication of Thin Film Dye Sensitized Solar Cells with Solar to Electric Power Conversion Efficiency over 10\%. Thin Solid Films 2008, 516, 4613-4619.

(7) Hao, F.; Dong, P.; Luo, Q.; Li, J.; Lou, J.; Lin, H. Recent Advances in Alternative Cathode Materials for Iodine-Free DyeSensitized Solar Cells. Energy Environ. Sci. 2013, 6, 2003.

(8) Watson, D. F.; Meyer, G. J. Electron Injection at Dye-Sensitized Semiconductor Electrodes. Annu. Rev. Phys. Chem. 2005, 56, 119-156.

(9) Anderson, A. Y.; Barnes, R. F.; Durrant, J. R.; O 'regan, B. C. Quantifying Regeneration in Dye-Sensitized Solar Cells. J. Phys. Chem. C 2011, 115, 2439-2447.

(10) Hagfeldt, A.; Boschloo, G.; Sun, L.; Kloo, L.; Pettersson, H. Dye-Sensitized Solar Cells. Chem. Rev. 2010, 110, 6595-6663.

(11) Haque, S. A.; Palomares, E.; Cho, B. M.; Green, A. N. M.; Hirata, N.; Klug, D. R.; Durrant, J. R. Charge Separation versus Recombination in Dye-Sensitized Nanocrystalline Solar Cells: The Minimization of Kinetic Redundancy. J. Am. Chem. Soc. 2005, 127, $3456-3462$.

(12) Boschloo, G.; Hagfeldt, A. Characteristics of the Iodide/ Triiodide Redox Mediator in Dye-Sensitized Solar Cells. Acc. Chem. Res. 2009, 42, 1819-1826.

(13) Clifford, J. N.; Martínez-Ferrero, E.; Viterisi, A.; Palomares, E. Sensitizer Molecular Structure-Device Efficiency Relationship in Dye Sensitized Solar Cells. Chem. Soc. Rev. 2011, 40, 1635-1646.

(14) Mathew, S.; Yella, A.; Gao, P.; Humphry-Baker, R.; Curchod, B. F. E.; Ashari-Astani, N.; Tavernelli, I.; Rothlisberger, U.; Nazeeruddin, M. K.; Grätzel, M. Dye-Sensitized Solar Cells with 13\% Efficiency
Achieved through the Molecular Engineering of Porphyrin Sensitizers. Nat. Chem. 2014, 6, 242-247.

(15) Polander, L. E.; Yella, A.; Curchod, B. F. E.; Ashari Astani, N.; Teuscher, J.; Scopelliti, R.; Gao, P.; Mathew, S.; Moser, J.-E.; Tavernelli, I.; Rothlisberger, U.; Grätzel, M.; Nazeeruddin, M. K.; Frey, J. Towards Compatibility between Ruthenium Sensitizers and Cobalt Electrolytes in Dye-Sensitized Solar Cells. Angew. Chem., Int. Ed. 2013, 52, 8731-8735.

(16) Yao, Z.; Zhang, M.; Li, R.; Yang, L.; Qiao, Y.; Wang, P. A MetalFree N-Annulated Thienocyclopentaperylene Dye: Power Conversion Efficiency of $12 \%$ for Dye-Sensitized Solar Cells. Angew. Chem., Int. Ed. 2015, 54, 5994-5998.

(17) Yao, Z.; Zhang, M.; Wu, H.; Yang, L.; Li, R.; Wang, P. Donor/ Acceptor Indenoperylene Dye for Highly Efficient Organic DyeSensitized Solar Cells. J. Am. Chem. Soc. 2015, 137, 3799-3802.

(18) Gao, P.; Kim, Y. J.; Yum, J.-H.; Holcombe, T. W.; Nazeeruddin, M. K.; Grätzel, M. Facile Synthesis of a Bulky BPTPA Donor Group Suitable for Cobalt Electrolyte Based Dye Sensitized Solar Cells. J. Mater. Chem. A 2013, 1, 5535.

(19) Gao, P.; Tsao, H. N.; Yi, C.; Grätzel, M.; Nazeeruddin, M. K. Extended $\pi$-Bridge in Organic Dye-Sensitized Solar Cells: The Longer, the Better? Adv. Energy Mater. 2014, 4, 1301485.

(20) Ganesan, P.; Yella, A.; Holcombe, T. W.; Gao, P.; Rajalingam, R.; Al-Muhtaseb, S. a; Grätzel, M.; Nazeeruddin, M. K. Unravel the Impact of Anchoring Groups on the Photovoltaic Performances of Diketopyrrolopyrrole Sensitizers for Dye-Sensitized Solar Cells. ACS Sustainable Chem. Eng. 2015, 3, 2389-2396.

(21) Clark, C. C.; Marton, A.; Meyer, G. J. Evidence for Static Quenching of MLCT Excited States by Iodide. Inorg. Chem. 2005, 44, 3383-3385.

(22) Marton, A.; Clark, C. C.; Srinivasan, R; Freundlich, R. E.; Narducci Sarjeant, A. A.; Meyer, G. J. Static and Dynamic Quenching of $\mathrm{Ru}$ (II) Polypyridyl Excited States by Iodide. Inorg. Chem. 2006, 45, $362-369$.

(23) Rowley, J. G.; Farnum, B. H.; Ardo, S.; Meyer, G. J. Iodide Chemistry in Dye-Sensitized Solar Cells: Making and Breaking I-I Bonds for Solar Energy Conversion. J. Phys. Chem. Lett. 2010, 1, 3132-3140.

(24) Gardner, J. M.; Giaimuccio, J. M.; Meyer, G. J. Evidence for Iodine Atoms as Intermediates in the Dye Sensitized Formation of I-I Bonds. J. Am. Chem. Soc. 2008, 130, 17252-17253.

(25) Clifford, J. N.; Martínez-Ferrero, E.; Palomares, E. Dye Mediated Charge Recombination Dynamics in Nanocrystalline TiO2 Dye Sensitized Solar Cells. J. Mater. Chem. 2012, 22, 12415-12422.

(26) O’Regan, B. C.; Walley, K.; Juozapavicius, M.; Anderson, A.; Matar, F.; Ghaddar, T.; Zakeeruddin, S. M.; Klein, C.; Durrant, J. R. Structure/Function Relationships in Dyes for Solar Energy Conversion: A Two-Atom Change in Dye Structure and the Mechanism for Its Effect on Cell Voltage. J. Am. Chem. Soc. 2009, 131, 3541-3548.

(27) Miyashita, M.; Sunahara, K.; Nishikawa, T.; Uemura, Y.; Koumura, N.; Hara, K.; Mori, A.; Abe, T.; Suzuki, E.; Mori, S. Interfacial Electron-Transfer Kinetics in Metal-Free Organic DyeSensitized Solar Cells: Combined Effects of Molecular Structure of Dyes and Electrolytes. J. Am. Chem. Soc. 2008, 130, 17874-17881.

(28) Bai, Y.; Zhang, J.; Zhou, D.; Wang, Y.; Zhang, M.; Wang, P. Engineering Organic Sensitizers for Iodine-Free Dye-Sensitized Solar Cells: Red-Shifted Current Response Concomitant with Attenuated Charge Recombination. J. Am. Chem. Soc. 2011, 133, 11442-11445.

(29) Zhang, M.; Liu, J.; Wang, Y.; Zhou, D.; Wang, P. Redox Couple Related Influences of $\pi$-Conjugation Extension in Organic DyeSensitized Mesoscopic Solar Cells. Chem. Sci. 2011, 2, 1401.

(30) Robson, K. C. D.; Hu, K.; Meyer, G. J.; Berlinguette, C. P. Atomic Level Resolution of Dye Regeneration in the Dye-Sensitized Solar Cell. J. Am. Chem. Soc. 2013, 135, 1961-1971.

(31) Swords, W. B.; Simon, S. J. C.; Parlane, F. G. L.; Dean, R. K.; Kellett, C. W.; Hu, K.; Meyer, G. J.; Berlinguette, C. P. Evidence for Interfacial Halogen Bonding. Angew. Chem., Int. Ed. 2016, 55, 59565960. 
(32) Mishra, A.; Fischer, M. K. R.; Bäuerle, P. Metal-Free Organic Dyes for Dye-Sensitized Solar Cells: From Structure: Property Relationships to Design Rules. Angew. Chem., Int. Ed. 2009, 48, 2474-2499.

(33) Malytskyi, V.; Simon, J.-J.; Patrone, L.; Raimundo, J.-M. Thiophene-Based Push-pull Chromophores for Small Molecule Organic Solar Cells (SMOSCs). RSC Adv. 2015, 5, 354-397.

(34) O’Regan, B. C.; Durrant, J. R. Kinetic and Energetic Paradigms for Dye-Sensitized Solar Cells: Moving from the Ideal to the Real. Acc. Chem. Res. 2009, 42, 1799-1808.

(35) Aghazada, S.; Gao, P.; Yella, A.; Marotta, G.; Moehl, T.; Teuscher, J.; Moser, J.-E.; De Angelis, F.; Grätzel, M.; Nazeeruddin, M. K. Ligand Engineering for the Efficient Dye-Sensitized Solar Cells with Ruthenium Sensitizers and Cobalt Electrolytes. Inorg. Chem. 2016, 55, 6653-6659.

(36) Teuscher, J.; Marchioro, A.; Andrès, J.; Roch, L. M.; Xu, M.; Zakeeruddin, S. M.; Wang, P.; Grätzel, M.; Moser, J.-E. Kinetics of the Regeneration by Iodide of Dye Sensitizers Adsorbed on Mesoporous Titania. J. Phys. Chem. C 2014, 118, 17108-17115.

(37) Jeon, J.; Goddard, W. A., III; Kim, H. Inner-Sphere ElectronTransfer Single Iodide Mechanism for Dye Regeneration in DyeSensitized Solar Cells. J. Am. Chem. Soc. 2013, 135, 2431-2434.

(38) Jeon, J.; Park, Y. C.; Han, S. S.; Goddard, W. A., III; Lee, Y. S.; Kim, H. Rapid Dye Regeneration Mechanism of Dye-Sensitized Solar Cells. J. Phys. Chem. Lett. 2014, 5, 4285-4290.

(39) Fabregat-Santiago, F.; Bisquert, J.; Garcia-Belmonte, G.; Boschloo, G.; Hagfeldt, A. Influence of Electrolyte in Transport and Recombination in Dye-Sensitized Solar Cells Studied by Impedance Spectroscopy. Sol. Energy Mater. Sol. Cells 2005, 87, 117-131.

(40) Fabregat-Santiago, F.; Garcia-Belmonte, G.; Mora-Seró, I.; Bisquert, J. Characterization of Nanostructured Hybrid and Organic Solar Cells by Impedance Spectroscopy. Phys. Chem. Chem. Phys. 2011, 13, 9083.

(41) Wang, Q.; Moser, J.; Grätzel, M. Electrochemical Impedance Spectroscopic Analysis of Dye-Sensitized Solar Cells. J. Phys. Chem. B 2005, 109, 14945-14953.

(42) Zhang, J.; Yao, Z.; Cai, Y.; Yang, L.; Xu, M.; Li, R.; Zhang, M.; Dong, X.; Wang, P. Conjugated Linker Correlated Energetics and Kinetics in Dithienopyrrole Dye-Sensitized Solar Cells. Energy Environ. Sci. 2013, 6, 1604.

(43) Cai, N.; Li, R.; Wang, Y.; Zhang, M.; Wang, P. Organic DyeSensitized Solar Cells with a Cobalt Redox Couple: Influences of $\pi$ Linker Rigidification and Dye-bath Solvent Selection. Energy Environ. Sci. 2013, 6, 139.

(44) Fabregat-Santiago, F.; Bisquert, J.; Palomares, E.; Otero, L.; Kuang, D.; Zakeeruddin, S. M.; Grätzel, M. Correlation between Photovoltaic Performance and Impedance Spectroscopy of DyeSensitized Solar Cells Based on Ionic Liquids. J. Phys. Chem. C 2007, 111, 6550-6560. 



\section{Supporting information for}

Unravelling the Dual Character of Sulfur Atoms on Sensitizers in the DyeSensitized Solar Cells.

Sadig Aghazada, ${ }^{1}$ Peng Gao, ${ }^{1}$ Aswani Yella, ${ }^{2}$ Thomas Moehl, ${ }^{2}$ Joël Teuscher, ${ }^{3}$ Jacques-E. Moser, ${ }^{3}$ Michael Grätzel, ${ }^{2}$ and Mohammad Khaja Nazeeruddin. ${ }^{1 *}$

1. Group for Molecular Engineering of Functional Materials, Institute of Chemical Sciences and Enginering, École Polytechnique Fédérale de Lausanne, CH-1950 Sion, Switzerland.

2. Laboratory of Photonics and Interfaces, Institute of Chemical Sciences and Enginering, École Polytechnique Fédérale de Lausanne, Station 6, CH-1015 Lausanne, Switzerland.

3. Group for Photochemical Dynamics, Institute of Chemical Sciences and Enginering, École Polytechnique Fédérale de Lausanne, Station 6, CH-1015 Lausanne, Switzerland. 


\section{Electrochemical Impedance Spectroscopy.}
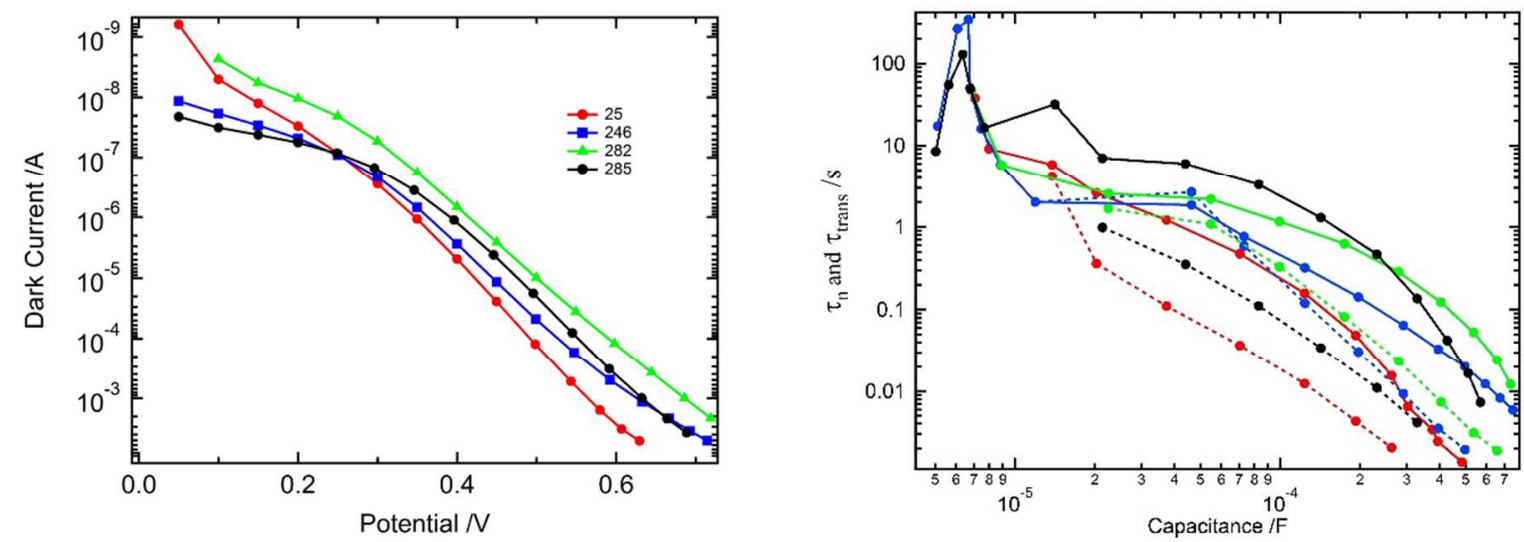

Figure S1. Some parameters extracted from EIS analyses.

(left) Dark current over potential; (right) transport (dashed) and recombination (solid) lifetimes versus capacitance. In both figures, lines with red, blue, green and black colors refer to the devices with SA25, SA246, SA282 and SA285 respectively. 
Transient Absorbance Spectroscopy
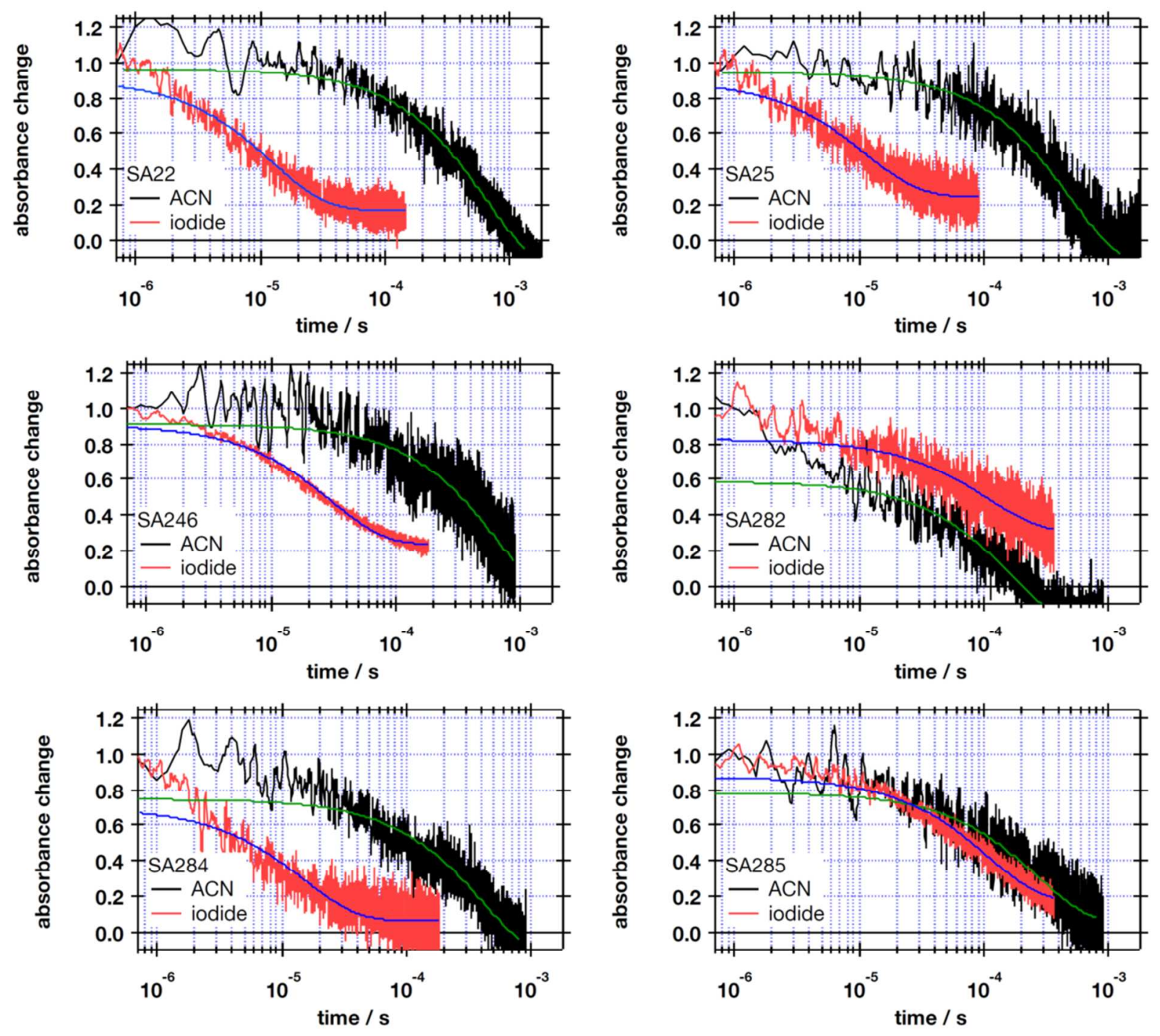

Figure S2. Normalized nanosecond transient absorbance decays. Red and black decays refer to the cells with and without sensitizer. Green and blue lines are fits. 